\title{
Identifyng the relationships between personality traits and non-cognitive skills
}

\author{
Călin Mariana Floricica \\ "Ovidius" University of Constanța, Romania \\ fmarianacalin@gmail.com \\ Radu Andrei Mihai \\ "Ovidius" University of Constanța, Romania \\ anduxsg@gmail.com
}

\begin{abstract}
Through this research, it has been studied the relationship between personality traits and non-cognitive skills. The hypotheses of this study are that there is a positive correlation between a high level of extraversion and physical abilities, and there is a positive correlation between a high level of autonomy and musical abilities. The research was conducted through two research tools, the purpose of which was to identify and evaluate personality traits and non-cognitive skills. The group of participants consists of 120 people aged between 18 and 33 years. The study results attest the validity of the assumptions. In both cases, personality traits are a possible predictor of the development of non-cognitive skills, while the latter are a possible modeling factor for the personality.
\end{abstract}

Keywords. personality traits, non-cognitive skills, autonomy, musical abilities, extraversion, physical abilities.

\section{Introduction}

The personality term comes from the Latin "persona", which represents the name of the theater masks used by the romans actors when they were performing Greek theater pieces. The role of the mask consists in designing a role or a certain type of appearance, but from a psychological point of view, the concept of "personality" is more than that (Feist \& Feist, 2006). With the evolution of this term, "persona" it became the word that represents the actor behind the mask, thus "bringing together internal psycho-moral and psycho-physical features" (Golu, 2007, p. 753). One possibility of explaining the personality concept is that it represents a series of "consistent patterns of intrapersonal behaviors and processes from the individual" (Burger, 2019) ${ }^{1}$. According to the same author, these patterns constitute individual differences between humans, while intrapersonal processes designate the totality of emotional, motivational and cognitive processes that influence how the individual acts and feels.

\footnotetext{
${ }^{1},(. .$.$) consistent behavior patterns and interpersonal processes originating within the individual."$
} 
Other personality definitions tell us that this is "a stable element of a person's conduct; what characterizes and differentiates it from another person." (Sillamy, 2000, p. 231) or "a macro system of informational and operational invariants that are constantly expressed in conduct and are defining or characteristics of the subject" (Neveanu-Popescu , 1978, p. 533). In other words, personality is the result of man's total development as well as the valorization of his own attributes in the social sphere, being the conscious response of the individual to the environment and the surrounding reality (Chetan \& Sommer, 1978). So, personality is seen as a set of "stable, perceptive, reporting and thinking patterns about the environment and the self that are expressed in a wide variety of social and personal contexts." (American Psychiatric Association, 2000, pp. 686, and Joyce, 2010, p. 4).

When we refer to the concept of trait, we relate directly to a personality dimension that we use to classify the people around us, according to the degree of manifestation of their particular behavioral characteristics (Burger, 2019). Each person benefits from a series of individual characteristics, such as shame or aggression, which constitute long-term provisions or features that, can be used to characterize human personality (Engler, 2014). Gordon Allport considers the traits to be those human tendencies to respond to events in the outside world in a certain way. The traits are consistent and resilient, representing the ultimate reality of the psychic organization. At the same time, they are divided into two categories: common features and personal arrangements. First refers to a hypothetical construct through which it is possible to compare individuals from different cultures, while the latter refers to a determinant general characteristic of the person only belonging to it. Also, three categories are recorded at the level of personal provisions: the cardinal dispositions, which refer to the fact that almost all the behaviors of an individual are under the influence of an omnipresent personal disposition; the central dispositions, which refer to the characteristic tendencies of the human individual, which he could use in the process of describing his essential characteristics; secondary dispositions, which refer to specific trends, rather than crucial in terms of the structure of human personality (Engler, 2014).

In psychology there is some confusion in terms of aptitude and abilities. The term aptitude should be used when we refer to a collection of skills that have a certain value in a culture. From a theoretical point of view, the concept of "skills" refers to the possession of abilities that have been acquired through experience or training, while the concept of "abilities" represents the potential inurement of such skills (Kline, 2000). A specific distinction between the two concepts can be achieved through their definitions. Thus, aptitude is an " attribute or a system of attributes of the subject, mediating the success in an activity; the possibility to act and achieve performance; a factor of the person facilitating knowledge, practice, technical and artistic elaboration, communication." (Neveanu-Popescu, 1978, p. 58), while the ability refers to that "trait synonymous with understanding, dexterity, skillfulness, cleverness, highlighting the ease, speed, superior quality and precision with which man performs certain activities, involving self-organization appropriate to the concrete task, supple, efficient adaptation. It is frequently reported in the case of muscular, manual actions, thus having the meaning of method, working pattern or behavior for concrete tasks. It is also noticeable for cognitive tasks." (Ibid, P.58). In other words, abilities are those (non) cognitive characteristics that can be developed and perfected, and will result in skills, which in turn represent a system of attributes or inclinations that enable the individual to successfully perform certain activities, but also to achieve performance in a certain field.

Non-cognitive skills are those abilities that can be identified outside of the cognitive sphere, but which make a significant contribution to the individual's success in successfully completing some activities. In this concept it fits both abilities that refers to the physiological 
and sensorial sphere, as well as self-regulation or relating with other people (Miclea \& Călinici, 2008). Non-cognitive skills have several facets: some of them refer to personal and social competence, while others refer to affectivity (Khine, 2016). Compared to cognitive abilities that crystallize during the development period, non-cognitive abilities can be learned and developed even after the development or study periods have passed through the practice of those activities that enable them to be appropriated (Humphreys, Kesenne, \& Rodríguez, 2011). Conceptualizing non-cognitive abilities takes place from 1920 to 1930 through some constructs such as "social intelligence" (Thorndike) or physical, psycho-motors, and sensorial abilities (Fleishman), as well as through the operationalization of musical and artistic talents. Fifty years after these constructs, Gardner introduces the concept of "multiple intelligence," while Sternberg defines "practical intelligence," which allows to organize these types of abilities in the form of constructs. In Gardner's perspective, "multiple intelligence" refers to linguistic, musical / rhythmic, naturalistic, logical / mathematical, spatial / visual, kinesthetic / intrapersonal, interpersonal and existential intelligence (Gardner 1988; Sternberg 1996; Miclea \&, 2008).

Non-cognitive abilities are divided into two dimensions: personal dimension and social dimension. Within each dimension, there are other sub dimensions as follows (Balica, et al.):

Personal dimension - which contains five sub dimensions:

1. The concept of self: meaning, the way the person perceives himself. Here falls the academic self (the way of mental representation of personal academic ability) and the social self (the way in which the human individual perceives the existence of social acceptances, but also his own inter-relational abilities (Brunner et. al., 2009, Brendt \& Burgy, 1996; apud. Ibid.) In this context, self-consciousness, defined as "the essential condition of regulator activism, selectivity and creative intervention in the environment," (Neveanu-Popescu, 1978, p. 141), but also how the human individual pays attention to the internal and external aspects of the self. Also, within the concept of self is also the body image, meaning the way of representation of the information regarding the personal physical aspect (Delevecchio et al., 2015; 2013, Balica et al., 2019).

2. Self-efficacy: which refers to the way in which the human individual self-assesses his / her own capacity to organize and execute the actions necessary for the accomplishment of objectives, being in close connection with the sense of ownership (Bandura, 1977; 1955; 1997; apud. Ibid.).

3. Self-regulation: is that human self-control capacity, both at the physical (behavioral) and cognitive level.

4. Motivation: represents the totality of dynamic factors involved in defining a person's behaviors.

5. Creativity: that is, the "a mood to create that exists in a potential state of the individual and of all ages." (Sillamy, 2000, p. 84).

Social dimension - which contains two sub dimensions:

1. Social skills: meaning, "those learned behaviors accepted in society that allow a person to interact with others effectively and to avoid unacceptable reactions by society" (Greshman \& Elliot, 1990, Balica et al., P. 38). In the case of these abilities, it is both the disposition and the capacity of the individual to initiate and conduct pro-social behaviors, but also to maintain effective and beneficial interpersonal relationships for each partner involved. 
2. Civic Skills: refers to the ability of the individual to take part in the activity of civic life, which implies effective involvement with other people in public activities, a high degree of responsibility and solidarity, as well as an active interest in what solving existing problems at the local community level or community in a broad sense along with the manifestation of respect for human rights as well as differences between the values of different ethnic or religious groups (Ibid.).

Given that this research addresses two personality traits involved with non-cognitive skills, I think that explanations are needed as to what these traits and abilities are. Regarding the features, we will first discuss autonomy, one of the five surface areas of the Big Five model. The last one is considered to be independent from cognitive aptitudes. Within it are grouped different types of behaviors that are considered to have a direct connection with an active search for love and new experiences. Autonomy describes the (non) cognitive opening to experiences. Its manifestation takes place in a wide range of interests and through the search and experimentation of novel activities (McCrae \& Allik, 2002). In general, people with a high level of autonomy tend to act differently from others, but also an interest in using creativity to carry out their activities. At the same time, an increased level of autonomy implies the existence of a desire for independence and freedom of action and development.

Regarding extroversion, it is necessary to understand that this is one of the temperamental concepts of human personality, along with introversion. A definition of temper tells us that it is the "dynamic-energetic side of personality. Dynamic because it provides us with information about how fast or slow, mobile or rigid, accelerated or flat, uniform or nonuniform is the individual's conduct. Energetic, because it shows us how much energy an individual has and how it is consumed. (...) Temper is one of the sides of the personality that most expresses in behavior and conduct (movements, affective reactions, speech, etc.)" (Zlate, 2006, p.353). Basically, when we talk about temper we refer to all those characteristics of manifestation of the emotional phenomena, within which the capacities of the individual of emotional stimulation are found, together with his speed of response and the quality of the predominant state, as well as the particularities of manifestations of fluctuations and the intensity of the mental state (Allport, 1961, p. 34 ap Joyce, 2010, p. 4).

In this sense, extraversion is the man personality oriented towards the outside. Extraversion is the "outward orientation of libido. (...) an obvious relationship of the subject with the object in the sense of a positive displacement of the subjective interest towards the object. Someone who is in an extraverted state thinks, feels and acts in relation to the object, namely in a straightforward and clearly perceptible way (...). Extraversion is therefore to some extent a transfer of interest from subject to object. If extraversion is intellectual, then the subject thinks of itself in the object; if she is affective, the subject feels herself in the object. In the state of extraversion, the subject is strongly determined (...) by the object." (Jung, 2004, pp. 448-449). At the same time, extraversion refers to the quantity and intensity of an individual's relationships with his / her environment (especially from a social point of view), but also to the energetic, enthusiastic and secure tendency to search for contacts with the environment, along with the positive experience of his own experiences (McCrae \& amp; Allik, 2002). An extravert tends to display positive feelings when in the social environment, as well as an increased interest in active participation in social events or group entertainment. Extraversion also involves the high tendency to initiate and develop dialogues with other people, along with establishing effective relationships with them.

In terms of non-cognitive abilities, two of these are evaluated in this research: musical abilities and physical abilities. Firstly, musical abilities refer to the individual's ability to successfully perform tasks that require the reception, production and use of musical sounds. 
They relate to the individual's potential to learn to create music and they have a number of features such as: rhythm pattern, musical memory, rhythm sense, time sense, timbre sensation, sensitivity for sound intensity, auditory and musical production and the sense of harmony (consonance / dissonance) (Miclea \& Călinici, 2008). Secondly, physical abilities refer to the individual's ability to successfully complete a series of activities in which the intense sustained physical effort, sustainability, speed and detention are required in terms of physical responses. They relate to force, strength, balance and body coordination, being identified by the following features: dynamic flexibility, dynamic force, explosive force, static force, trunk strength, extensible flexibility, general body coordination, general body balance and physical strength (ibid.).

\section{Sample and methods}

The sample of this research consists of 120 persons, both male (53 participants $44.2 \%$ of the total) and female (67 participants $-55.8 \%$ of the total), with ages between 18 and 33 years. It is worth mentioning that most of the participants (namely $77.5 \%$ of the total) are aged between 18 and 22 years. A total of 100 participants $(88.3 \%)$ of the sample come from the urban area, while only 20 participants $(16.7 \%)$ come from rural areas. Regarding civil status, 18 of the participants (15\%) are married, while 102 of the participants $(85 \%)$ are unmarried. At the same time, 100 of the participants completed the level of secondary education (high school), while 20 of them completed the level of higher education (faculty).

The methods used in this study consisted of two questionnaires aimed at identifying and evaluating personality traits and non-cognitive abilities.

\subsection{Five-factor personality inventory (f.f.p.i.)}

This questionnaire aims to evaluate the five factors of the Big Five Model: extraversion, kindness, conscientiousness, emotional stability and autonomy. The use of this questionnaire can be done through both self-evaluation and evaluation of the subject by another person authorized to use it. In the questionnaire, there are 100 items that are grouped in five scales (those that designate the Big Five surface). Each scale benefits from 20 items. Five answers are available to answer the questions, using a Likert scale, where "1" means "it fits me a lot", "2" means "it fits me a little", "3 means" fits me half "," 4 "means" it fits well"and" 5 "means" it fits me a lot ". Some items are inversely quoted. The questionnaire does not have a limited time to complete.

\subsection{Questionnaire for assessment of non-cognitive abilities}

The questionnaire aims to identify non-cognitive abilities that contribute to the success of the individual. It benefits from a total of seven scales, which include 58 items. These seven scales are the following: 1) Physical abilities (10 items); 2) Psycho-motor abilities (10 items); 3) Visual abilities (6 items); 4) Auditive abilities (6 items); 5) Musical abilities (8 items); 6) Artistic abilities (8 items); 7) Interpersonal abilities (10 items). Response variants are offered through a Likert scale where "1" means "very weak", "2" means "weak", "3" means "medium", "4" means "good" and "5" means "very good". The questionnaire can be done individually, but also in the group. He does not have a time limit for completing it. Subjects should self-assess these abilities.

\section{Objectives and hypotheses}

The main objective of this research is to identify the existing relationships between personality traits and non-cognitive abilities while the secondary objective is to identify the 
manifestation particularities of the correlative phenomena, as well as, the reasons that explain the existence of these phenomena. Thus, the assumptions of the research are as follows:

Hypothesis no. 1: It is assumed that there is a positive correlation between a high level of extraversion and physical abilities.

Hypothesis no. 2: It is assumed that there is a positive correlation between a high level of autonomy and musical abilities.

\section{Results}

Hypothesis no. 1: It is assumed that there is a positive correlation between a high level of extraversion and physical abilities.

The first hypothesis of this research was statistically confirmed by calculating the Pearson correlation coefficient. The value of this coefficient is 0.271 , indicating that this correlation is significant at $\mathrm{p}<0.05$ (see Table 1). In this case, we can conclude that there is a positive correlation between extraversion and physical abilities.

\section{Correlations}

\begin{tabular}{|ll|r|r|}
\hline & & Extraversiune & Abilitati_fizice \\
\hline \multirow{2}{*}{ Extraversiune } & Pearson Correlation & 1 &, $271^{* *}$ \\
& Sig. (2-tailed) & &, 003 \\
& $\mathrm{~N}$ & 120 & 120 \\
& Pearson Correlation &, $271^{* *}$ & 1 \\
Abilitati_fizice & Sig. (2-tailed) &, 003 & \\
& $\mathrm{~N}$ & 120 & 120 \\
\hline
\end{tabular}

**. Correlation is significant at the 0.01 level (2-tailed).

The result of the statistical correlation between extraversion and physical abilities Table 1

Also, this positive correlation can also be observed through the cloud of points, where the results start from left to right, from bottom to top, as can be seen in Figure 1.

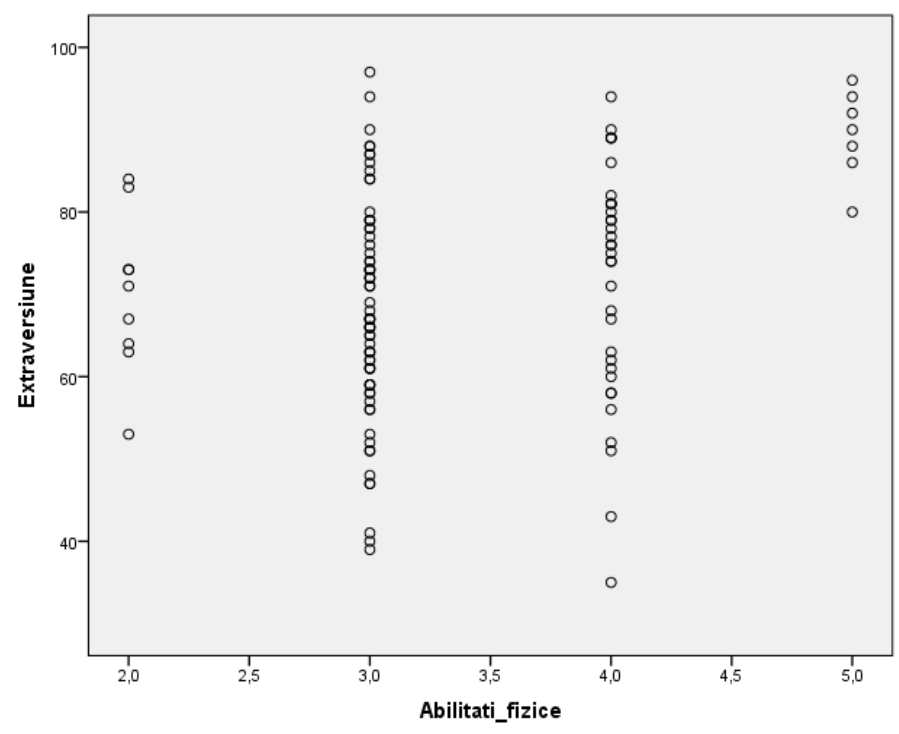

Fig.1. The cloud of correlation between extraversion and physical abilities 
Certainly, as we can identify through other studies (Rhodes \& Boudreau, 2019), (Rhodes \& Smith, 2006), (Tolea, et al., 2012), (Wuts \& Dishman, 2015), (Sutin, Stephan, Artese, Oshio, \& Terracciano, 2016), there is a positive correlation between extraversion and physical abilities. It is important to understand the reasons for this phenomenon if we want to accurately identify how this correlation works. To begin with, the explanation is that physical abilities implicitly imply the external orientation of both physical and psychic energy as well as the activity the human individual carries out when he uses his or her respective abilities. Every physical movement, as well as every individual's behavior that benefits from these abilities, requires a process of exteriorization and orientation of activity towards the external environment. Considering that extraversion involves an orientation of psychic energy towards the outside, the correlation between the two variables is plausible.

Another response can be identified through the manifestations particularities of extraversion, specifically through the feature of this personality trait of creating a relationship between the subject and the objective. An extraverted person thinks feels and acts according to the perceived object, which means that through it a subject is transferred to the object. In the correlation of the two variables studied in this hypothesis, the subject is, of course, the human individual, while the object can be represented both by the activity of manifesting physical abilities and by the objects that require their use. In this case, Jung (2004) explains that extraversion can be of two kinds: active (when the subject intends) and passive (when the object imposes it). From the point of view of active extraversion, the relationship between it and physical abilities is the tendency of the subject and in his interest to exteriorize his mental energy, along with his intention to realize and execute certain types of activities or movements in relation to the perceived object (with the physical action needed to use the physical abilities or the element on which they act). From the point of view of passive extraversion, the relationship between it and physical abilities is determined by the fact that the object (the necessary physical action or the object requiring action on it) imposes on the subject the necessity of manifestation of the behavioral exteriorization as well as of the psychic energy.

Also, the correlation between the two variables can be explained by the fact that people with a high level of extraversion show an increased tendency towards a more active activity orientation than for those with a low level (Acevedo, 2012). Extraversion implies a trend towards action that requires a high level of activity, which implicitly leads to the formation of an active lifestyle. Activity is that mood aimed at a fast lifestyle, high energy, but also for doing more activities during the same day. Learning and developing physical abilities involves engaging in actions whose levels of activity are high, but also an active lifestyle that allows them to crystallize those abilities. The superiority of the activity manifestation in the case of increased extraversion is a determining factor for initiation and involvement in physical activities (Adams \& Mowen, 2005; Rhodes \& Courneya, 2003; Rhodes, Courney \& Jones, 2002; apud Rhodes \& Boudreau, 2019). Extraversion is positively associated with aerobic activities as well as the active environments of the activity unfolding such as swimming, dancing, or tennis, though there are no significant differences in other sporting activities such as running or cycling. Considering that a strong negative correlation was found between extraversion and inactivity (Wilson \& Dishman, 2015), and that extraversion involves a tendency towards more frequent initiation of physical activities, the relationship between it and physical abilities seems to be justified.

People with a high level of extraversion have a much higher level of satisfaction in achieving positive emotional states that arise as a result of doing physical activities, compared to those with low levels of extraversion. The latter do not perceive physical activity as an 
attractive source of rewards, which is why the level of motivation involved in initiating such activities is much lower. At the same time, the fact that extraverted people tend to spend fewer hours a day sitting down than introverted people seems to be an explanation for the existence of the correlation between extraversion and physical abilities (Wichers et al., 2012; Ebstrup, Aadahl, Eplov, Pisinger \& Jorgensen, 2013; Sutin, Stephan, Artes, Oshio, \& Terracciano, 2016).

An important factor in understanding the correlation between the two variables is self-esteem. According to several studies (Robinson \& Tracy, 2001), (Haugen, Safvenbom, \& Ommundsen, 2011), (Gilani \& Dashipour, 2016) and (Mikulášková \& Babincak, 2015) both extraversion and holding the physical abilities register a positive correlation with high selfesteem. Of course, this high self-esteem facilitates the initiation and establishment of interpersonal relationships in the case of an extraverted, as well as its need to be at the center of attention and to be remarked in various situations. These needs are a factor facilitating the learning and development of physical abilities that can be used to improve self-esteem.

The existing tendency in the case of an increased level of extraversion, to orient mental energy externally, therefore to express extrinsically internal experiences, is an important factor in understanding the relationship between the two variables. Physical abilities facilitate the physical activities that allow for the exteriorization of the inner feelings or tensions that the human individual accumulates over time. Mental energy is then oriented towards activity facilitated by physical abilities, thus allowing the discharge of that energy through physical activity. For example, performing physical activities produces a $87 \%$ reduction in stress and a reduction in headache frequency of 52\% (Hansmann, Hug, \& Seeland, 2007). There is a neurochemical base at exercise level: these exercises have the ability to reduce the level of stress-producing hormones such as adrenaline or cortisone, stimulating endorphin production, which contributes to the feeling of relaxation and the state of "good" that people tend to feel after exercising (Harvard Medical School, 2011). It has also been reported that after 20 to 30 minutes of exercise, people tend to feel calmer for a few hours after the end of that activity. This is because physical activity alters hormonal and neurotransmitter responses, such as dopamine or serotonin, which have a strong effect on the mental state and the behavior of a person's behavior (Jackson, 2013).

At the same time, it is important to keep in mind the social aspect that interferes with the relationship between the two variables. A person with a high level of extraversion seeks and establishes as many interpersonal relationships as possible, getting pleasure from interacting with other people, but also as part of social activities. Given that physical abilities are developed through the orientation towards active action environments and that these environments often involve the existence of other people around, then we can deduce that extraversion correlates positively with physical abilities through opportunities interaction that the activities necessary for their development provide.

However, as can be seen through these explanations, the correlation between extraversion and physical abilities is not direct. There are a number of factors or characteristics of both variables that interact with one another and which influence each other. The previous explanations are done in a general manner and represent a possible starting point for future research that will aim at accurately identifying those factors characteristic of those correlated variables.

Hypothesis no. 2: It is assumed that there is a positive correlation between a high level of autonomy and musical abilities. 
This second hypothesis was statistically confirmed by the results obtained from the calculation of the Pearson correlation coefficient, whose value is 0.238 , indicating that this correlation is significant at $\mathrm{p}<0.05$ (Table 2).

The result of statistical correlation between autonomy and musical abilities Table 2

\section{Correlations}

\begin{tabular}{|ll|r|r|}
\hline & & Autonomie & Abilitati_muzical \\
\hline \multirow{4}{*}{ Autonomie } & Pearson Correlation & 1 &, $238^{* *}$ \\
& Sig. (2-tailed) & &, 009 \\
& $\mathrm{~N}$ & 120 & 120 \\
& Pearson Correlation &, $238^{* *}$ & 1 \\
Abilitati_muzicale & Sig. (2-tailed) &, 009 & 120 \\
& $\mathrm{~N}$ & 120 & \\
\end{tabular}

**. Correlation is significant at the 0.01 level (2-tailed).

At the same time, the validity of this hypothesis can also be confirmed by the cloud of points (figure 2), which attests the placement of the results obtained from the left to the right of the figure, from the bottom up.

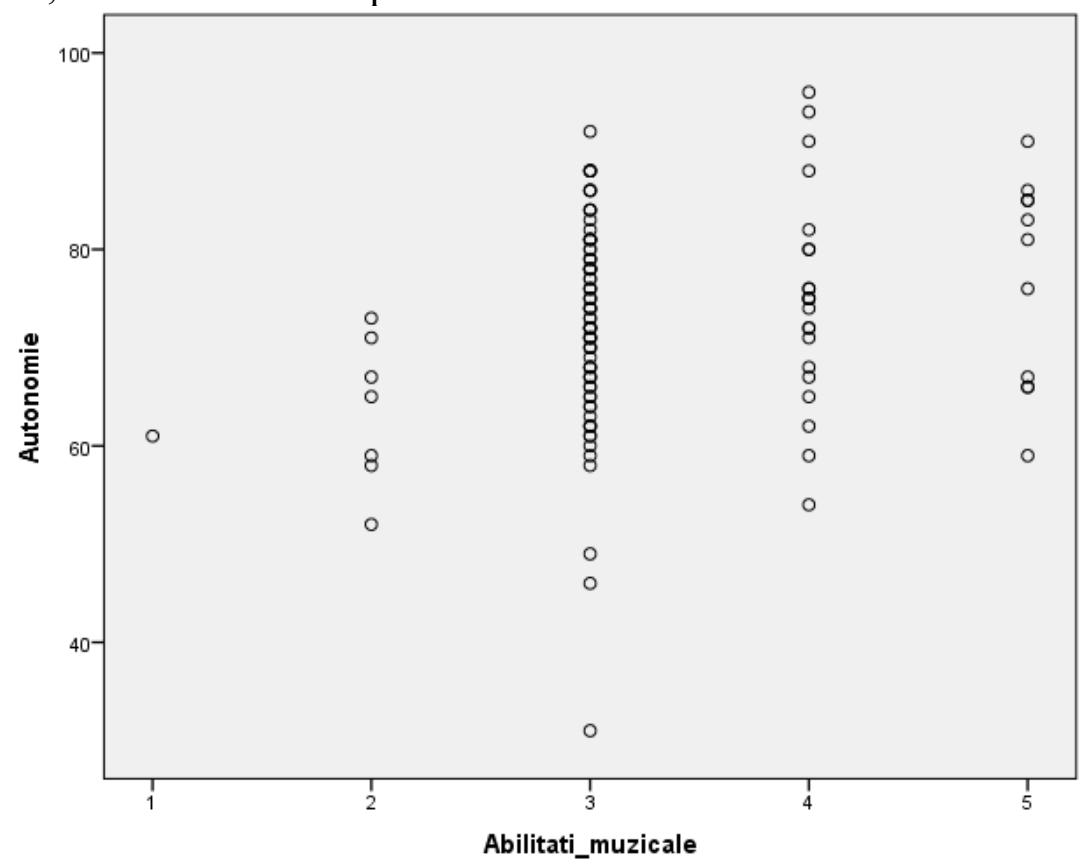

Fig. 2. The cloud of points of the correlation between autonomy and musical abilities

A first possible explanation of this phenomenon is the fact that a person with an increased level of autonomy manifests a frequent search for new experiences, and the musical abilities allow for a lively variety of experiences. Music is an infinite area of variety and uniqueness, representing " a supreme will of unity, for the breaking of individual barriers, not in the sense of disappearance of the individual, but by the disappearance of the limiting conditions imposed by the existence of this world." (Cioran, 2016, p.29). In this sense, the 
possibilities of experimentation are unlimited, and this allows the human person to overcome his current condition, but also experience unique and diverse experiences.

A feature of autonomy is that of aesthetic sensitivity, an active interest in music, art, or dance, which explains a possible link between musical abilities and this personality trait (Corrigall \& Schellenberg Glenn, Predicting who takes music lessons: parent and child characteristics, 2015). Musical abilities allows for a multitude of possibilities to achieve music, both through musical instruments and through the variety of genres and musical styles that a human individual can experience throughout his life. Through the use of musical instruments, these abilities facilitate freedom of action, development and expression, which is also valid for the sound varieties of musical notes used by the individual. Musical abilities facilitate the possibility of translating into a different form of human feelings, feelings and desires, and man's involvement in music implies an ample process of creativity and, according to the Hegelian perspective, a process by which the individuality subjectivity of its individuality is made, which leads to a meditation on the absolute subjectivity of absolute spirit and objectivity within the contingency domain (Biddle, 1995).

A high level of autonomy implies an existing desire to experiment with unique sensations and activities, and musical abilities allow the realization of these experiences through music that can give the human person a series of extraordinary and even ecstatic feelings. These types of experiences allow the human person to "break" from his own Self and experience the intensity, vibration, depth of musical sounds, and the mystical experience of the musical ritual and transcendence. Rhythmic repetitive stimulation has the ability to excite the limbic system and the autonomous system, which changes the particularities of functioning of psychic mechanisms such as sensation or thinking, but also the way the human individual perceives and interprets reality. In other words, the rhythms of music affect the neurological possibility of the brain to define its own limits (Newberg, D'Aquili, \& Rause, 2008). By practicing a musical instrument or interpreting a piece in a certain way, tensions or relaxations can occur in the muscles, and these activities lead to emotional responses being affected at times when they are repeatedly performed (Gelhorn \& Kiely, 1972, 1973 and Ibid.). Also, repetitive auditory stimuli can induce cortical rhythms that have the ability to both produce pleasant sensation experiences and to facilitate intense discharges at the level of excitement and resting systems (Walter \& Walter, 1949, pp. Ibid .). In this sense, the possibilities of experimentation of these experiences, together with their intensity, is a possible interest for a person with an increased level of autonomy, which may also represent a possible answer of the relationship between this personality trait and the musical abilities.

A high level of autonomy implies the possibility of using one's own creativity in working activities, along with the tendency to act differently from the way in which others act. Through the musical abilities, the individual can capitalize on all his creativity. The possibilities of playing back rhythmic patterns, auditory and musical production, or the sense of harmony are just some of the elements of musical abilities that allow the individual to manifest both his creativity and his individuality in what he / she means doing differently in comparison with those around. The existence of musical abilities involves the practice of a musical instrument or a certain type of music, and these things are learned through repetition. The repetition implies total involvement in the activity. Even in the case of music lovers, it takes hundreds or even thousands of hours of practice to learn to play an instrument or to learn techniques for making certain types of sounds or different styles of music. At the same time, we can add the need to know the theoretical and practical aspects of musical activity, along with the practice of certain pieces or to experiment with new individual approaches to the musical possibilities offered by the instrument (s) used. This learning process assumes the 
direct assumption of an attitude of openness to the possibilities offered by it. In order to form his musical skills, the human individual is obliged to form a wide openness, oriented towards the receptivity and acquisition of all the possibilities of musical manifestation offered by the instrument he is practicing. Acquiring new knowledge requires openness towards the artistic area, which affects the way in which human personality develops, facilitating the process of acquiring autonomy.

Possibility of independence and freedom in terms of the use of musical abilities and the making of music can be a facilitating factor on the basis of the formation of the autonomous personality through the dedication and total involvement of the human individual and his own individuality in terms of possibilities for realization of music.

Musical abilities not only involve the learning of action patterns, but also the direct involvement of the personal factor in the process of musical creation, which requires the development of originality and creativity to achieve it. In other words, music "forces" the development of personality in an autonomous manner. At the same time, to distinguish yourself through musical abilities, it is necessary to individualize and determine your own style, your own ways of acting and all elements that aim to differentiate from other people who have the same abilities, which is why the latter have the ability to influence the personality of the human individual in order to acquire those possibilities of individual manifestation and the necessity of differentiation in the musical plane, characteristics specific to autonomy.

As with the first hypothesis, it is necessary to understand that these explanations relate to the general characteristic of the correlation between increased levels of autonomy and musical abilities. As we can see, there are a number of secondary characteristics of each variable that interact and influences with one another. Even in this case, we can deduce that autonomy is a possible predictor of the development of musical abilities (Corrigall, Schellenberg, \& Misura, 2013), while the latter can play a role modeling personality traits.

\section{Conclusions}

The findings of this study show that there is a positive correlation between personality traits and non-cognitive abilities. This is due, first of all, to the fact that personality traits can be a predictor of the development of non-cognitive abilities. The prediction is determined by the traits characteristics and the respective ability: the learning and development of the latter must require the existence of certain personality characteristics whose particularity manifestations must be in accordance with the needs of non-cognitive ability. Secondly, the correlation between the variables studied is explained by the fact that non-cognitive abilities can represent a series of modeling factors in relation to human personality, having the ability to influence the way personality traits evolve and develop over time. Regarding the limits of this research, the first one is that the tools used allowed the general identification of the relationship between the variables studied. This is a difficulty, because the correlation phenomena explained above are manifested through the characteristics of the respective variables, of "substrates" that could not be precisely identified. At the same time, participants may have over / underrated their abilities, as the tool used to evaluate them is one that requires a self-assessment process. The potential development of this research consists in identifying and evaluating the "under-traits" and characteristics of the variables mentioned above, but also in identifying occupational interests that can play an essential role in understanding the correlation phenomena in this case. 


\section{References}

[1] Acevedo, O. E. (2012). The Oxford Handbook of Exercise Psychology. New York: Oxford University Press.

[2] Balica, M., Benga, O., Caragea, V., David-Crisbăşanu, S., Goia, D., Horga, I., \& Iftode, O. (n.d.). Dezvoltarea abilităților non-cogntiive la adolescenții din România. Retrieved from UNICEF: http://www.unicef.ro/wp-content/uploads/Dezvoltarea-abilitatilornoncognitive-29-aug-2016-pt-web-1.pdf. Accesat la data de 03.04.2019.

[3] Biddle, D. I. (1995). Autonomy, Ontology and the Ideal: Music Theory and Philosophical Aesthetics in Early Ninetheenth-Century German Thought. Tyne: Newcastle University Press.

[4] Burger, J. (2019). Personality. Boston: Wadsworth: Cengage Learning.

[5] Chețan, O., \& Sommer, R. (1978). Dicționar de filosofie. București: Editura Politică.

[6] Cioran, E. (2016). Cioran și muzica. București: Humanitas.

[7] Corrigall, A. K., \& Schellenberg Glenn, E. (2015, Martie 24). Predicting who takes music lessons: parent and child characteristics. Frontiers in Psychology.

[8] Corrigall, A. K., Schellenberg, G. E., \& Misura, M. N. (2013, Aprilie 30). Music training, cognition, and personality. Frontiers in Psychology.

[9] Engler, B. (2014). Personality Theories - An Introduction. Wadsworth: Cengage Learning.

[10] Feist, J., \& Feist, G. (2006). Theories of Personality. New York: The McGraw-Hill Companies, Inc.

[11] Gilani, M. R., \& Dashipour, A. (2016, Aprilie 15). The Effects of Physical Activity on Self-Esteem: A Comparative Study. Preluat de pe International Journal of High Risk Behaviors \& Addiction: http://jhrba.com/en/articles/13221.html. Accesat la data de 14.04.2019.

[12] Golu, M. (2007). Fundamentele psihologiei (Vol. 1). București: Editura Fundației România de Mâine.

[13] Hansmann, R., Hug, S.-M., \& Seeland, K. (2007). Restoration and stress relief through physical activities in forests and parks. Urban Forestry \& Urban Greening, 213 225.

[14] Harvard Medical School. (2011, Februarie). Exercising to relax. Preluat de pe Harvard Health Publishing: https://www.health.harvard.edu/staying-healthy/exercising-torelax

[15] Haugen, T., Safvenbom, R., \& Ommundsen, Y. (2011). Physical activity and global self-worth: The role of physical self-esteem indices and gender. Mental Health \& Physical Activity, 49 - 56.

[16] Humphreys, R. B., Kesenne, S., \& Rodríguez, P. (2011). The Economics of Sport, Health and Happiness: The Promotion of Well-being through Sporting Activities. Cheltenham: Edward Elgar Publishing Limited.

[17] Jackson, E. M. (2013). Stress Relief: The Role of Exercise in Stress Management. ACSM's Health \& Fitness Journal, 14 - 19.

[18] Joyce, D. (2010). Essentials of Temperament Assessment. New Jersey: John Wiley \& Sons, Inc.

[19] Jung, C. G. (2004). Tipuri psihologice. București: Editura Trei.

[20] Khine, S. M. (2016). Non-cognitive Skills and Factors in Educational Succes and Academic Achievement. In S. Areepattamannil, \& S. M. Khine, Non-cognitive Skills and Factors in Educational Attainment (pg. 3 - 9). Rotterdam: Sense Publishers.

[21] Kline, P. (2000). The Handbook of Psychological Testing. New York: Routledge. 
[22] McCrae, R. R., \& Allik, J. (2002). The Five-Factor Model of Personality Across Cultures. New York: Springer Sciene + Business Media, LLC.

[23] Miclea, M., \& Călinici, S. (2008). Manual pentru evaluarea abilităţilor noncognitive. Cluj-Napoca: Editura ASCR.

[24] Mikulášková, G., \& Babincak, P. (2015). Self-Esteem, Extraversion, Neuroticism and Health As Predictors of Quality of Life. Human Affairs, 411 - 420.

[25] Neveanu-Popescu, P. (1978). Dicționar de Psihologie. București: Editura Albastros.

[26] Newberg, A., D'Aquili, E., \& Rause, V. (2008). De ce nu dispare Dumnezeu: știința creierului și biologia credinței. București: Editura Curtea Veche.

[27] Rhodes, E. R., \& Boudreau, P. (2007, Aprilie 15). Physical Activity and Personality Traits. British Journal of Sports Medicine 40 (12), 958 - 965. Preluat de pe Oxford Research Encyclopedias: http://oxfordre.com/psychology/view/10.1093/acrefore/9780190236557.001.0001/acrefor e-9780190236557-e-210. Accesat la data de 14.04.2019.

[28] Rhodes, E. R., \& Boudreau, P. (2019, Aprilie 15). Physical Activity and Personality Traits. Preluat de pe Oxford Research Encyclopedias: http://oxfordre.com/psychology/view/10.1093/acrefore/9780190236557.001.0001/acrefor e-9780190236557-e-210. Accesat la data de 14.04.2019.

[29] Rhodes, E. R., \& Smith, E. N. (2006). Personality correlates of physical activity: a review and meta-analysis. British Journal of Sports Medicine 40 (12), 958 - 965.

[30] Robins, W. R., \& Tracy, L. J. (2001). Personality Correlates of Self-Esteem. Journal of Research in Personality, 463 - 482.

[31] Sillamy, N. (2000). Dicționar de Psihologie. București: Editura Univers Enciclopedic.

[32] Sutin, R. A., Stephan, Y. L., Artese, A., Oshio, A., \& Terracciano, A. (2016). The Five-Factor Model of Personality and Physical Inactivity: A Meta-Analysis of 16 Samples. Journal of Research in Personality, 22 - 28.

[33] Tolea, I. M., Terracciano, A., Simonsick, M. E., Metter, J. E., Costa Jr., T. P., \& Ferrucci, L. (2012). Associations between personality traits, physical activity level, and muscle strength. Journal of Research in Personality 46 (3), 264 - 270.

[34] Wilson, E. K., \& Dishman, K. R. (2015). Personality and physical activity: A systematic review and meta-analysis. Personality and Individual Differences 72, 230 242.

[35] Zlate, M. (2006). Fundamentele Psihologiei. București: Editura Universitară. 